\title{
Adding to the evidence or to the confusion: dual antithrombotic therapy in chronic coronary syndrome and atrial fibrillation
}

\author{
Shinwan Kany @ , Renate Schnabel
}

Atrial fibrillation (AF) is the most common arrhythmia in the world with the lifetime risk estimated to be $1 / 3$ in men and women over the age of 50 years. ${ }^{1}$ Cardiovascular disease, like misfortune, does not come singly in most cases. Coronary artery disease $(\mathrm{CAD})$ with the chronic coronary syndrome (CCS) or acute coronary syndrome (ACS) is a common comorbid condition. Management of patients with AF with a comprehensive treatment of risk factors and concomitant diseases is the key to treat these patients. Yet, the devil is in the details as treatment becomes increasingly complex.

Patients with $\mathrm{AF}$ and $\mathrm{CAD}$ require antiplatelet therapy (APT) in addition to oral anticoagulation (OAC) after myocardial infarction or percutaneous coronary intervention (PCI) for a limited time period. Depending on ischaemic risk, bleeding risk and unplanned PCI, different treatment regimens are available with dual antithrombotic therapy with OAC and APT up to 12 months. ${ }^{2}$ Looking at each possible combination of drugs and therapy length, the cardiologist is left with 2.8 million possible combinations in the first 12 months only. ${ }^{3}$

\section{PRECISION MEDICINE BUT TOO MANY OPTIONS WITH LOW EVIDENCE?}

This subanalysis from the recently published randomised controlled Atrial Fibrillation and Ischemic Events With Rivaroxaban in Patients With Stable Coronary Artery Disease Study' (AFIRE) by Fukaya et $a l^{4}$ examines whether aspirin or P2Y inhibitors (clopidogrel in 94.6\%) in addition to rivaroxaban impacts outcomes in patients with CCS. The main trial showed that dual antithrombotic therapy is associated with increased mortality compared with OAC monotherapy in patients with $\mathrm{AF}$ and CCS.

Cardiology, University Heart and Vascular Centre Hamburg-Eppendorf, Hamburg, Germany

Correspondence to Dr Shinwan Kany, Cardiology, University Medical Center Hamburg-Eppendorf, Hamburg 20246, Germany; s.kany@uke.de
Patients in the dual antithrombotic arm were compared in regard to additional APT (P2Y $\mathrm{Y}_{12}$ inhibitors $\mathrm{n}=297 \mathrm{vs}$ aspirin $n=778$ ) and a primary outcome of composite of stroke, systemic embolism, myocardial infarction, unstable angina requiring urgent revascularisation or death from any cause. No difference in the primary outcome was observed in patients receiving $\mathrm{P}_{2} \mathrm{Y}_{12}$ inhibitors or aspirin $(6.76 \%$ vs $5.28 \%, p=0.178)$. However, mortality was higher in the $\mathrm{P}_{2} \mathrm{Y}_{12}$ inhibitors group $(4.44 \%$ vs $2.85 \%$ per patientyear; $\mathrm{p}=0.041)$.

There is limited evidence in the comparison of aspirin with $\mathrm{P}_{2} \mathrm{Y}_{12}$ inhibitors in addition to OAC in patients with CCS. The AFIRE main trial showed that these patients do not benefit from additional APT, ${ }^{5}$ but doubts remain, and dual antithrombotic therapy is still common in clinical practice. ${ }^{6}$ The benefit seen with clopidogrel compared with aspirin in the monotherapy of patients undergoing PCI, recently shown with the 'Harmonizing Optimal Strategy for Treatment of Coronary Artery Stenosis-EXtended Antiplatelet Monotherapy (HOST-EXAM)' trial, is not evident in patients with AF in the analysis by Fukaya et al. ${ }^{4}$

Interpretation of this data is to be seen in the contexts of its many caveats. The AFIRE trial was randomised, but the comparison of $\mathrm{P} 2 \mathrm{Y}_{12}$ inhibitors and aspirin was not, as seen with significant baseline differences between the groups. The design was open label, which certainly can introduce bias. Also, the generalisability of the cohorts to European/ Western patients is limited. In particular, anticoagulant dosing is different here and significant numbers of patients received bare-metal stents (more than 30\% in the aspirin group) which is not standard of care anymore in the guidelines. General assumptions on $\mathrm{P}_{2} \mathrm{Y}_{12}$ inhibitors should be avoided, since almost $95 \%$ of patients with $\mathrm{P}_{2} \mathrm{Y}_{12}$ inhibitors received clopidogrel instead of more potent antiplatelet drugs like prasugrel or ticagrelor. Prescribing physicians in the AFIRE trial were free to prescribe more potent agents but may have feared a higher bleeding risk with prasugrel or ticagrelor.

Interestingly, the authors report no difference in major bleeding between both cohorts $(2.35 \%$ vs $2.95 \%$, $\mathrm{p}=0.456$ ) which again contrasts with the findings of HOST-EXAM where clopidogrel was associated not only with fewer thrombotic events $(3.7 \%$ vs $5.5 \%$, $\mathrm{p}=0.003)$ but also less bleeding $(2.3 \%$ vs $3.3 \%, p=0.003) .^{7}$ The pathophysiological background of aspirin-induced gastric bleeding is nicely explained by the inhibition of cyclo-oxygenase which not only leads to the desired inhibition of platelet-aggregator thromboxane $\mathrm{A}_{2}$ but also the synthesis of prostaglandins which are essential for gastric mucus secretion (figure 1).

One of the strengths in the work by Fukaya et al may be the utilisation of proton pump inhibitors (PPIs) in both cohorts $\left(64.3 \%\right.$ in the $\mathrm{P}_{2} \mathrm{Y}_{12}$ group and $62 \%$ in the aspirin group). In the 'Rivaroxaban for the Prevention of Major Cardiovascular Events in Coronary or Peripheral Artery Disease (COMPASS)' trial where rivaroxaban $2.5 \mathrm{mg}$ daily in addition to aspirin in stable atherosclerotic disease was shown to reduce cardiovascular mortality, an interesting substudy was conducted. Patients who were not on PPI at baseline were randomised to PPI or placebo resulting in two groups over 8000 patients with a mean follow-up of 3 years. Therapy with PPI was shown to be very safe without increase in cardiovascular events, cancer or pneumonia or dementia but a twofold increase of Clostridium difficile infections. ${ }^{8}$ The COGENT trial showed that concomitant therapy with PPI (in this case omeprazole) in patients with APT reduces gastrointestinal bleeding without a rise in thrombotic events. ${ }^{9}$ However, the most recent European Society of Cardiology (ESC) guidelines for management of ACS without ST-segment elevation (NSTEMI) do not recommend omeprazole due to concerns of inhibition of CYP2C19 and thus efficacy of clopidogrel. ${ }^{2}$

The ESC guidelines on management of AF mention PPIs without giving a level of recommendation akin to the NSTEMI guidelines. With the abundance of data supporting the use of PPI in patients with antiplatelet or dual antithrombotic therapy, they should be considered more frequently and guidelines have to provide more powerful recommendation. 


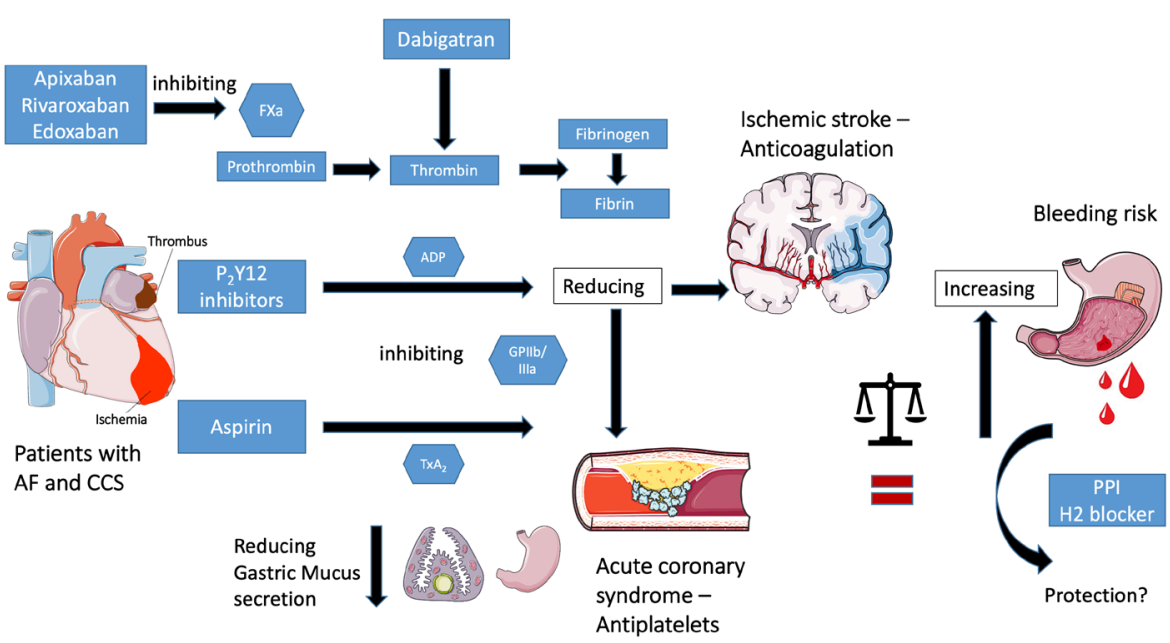

Figure 1 Overview about antiplatelet and anticoagulation mechanisms on haemostasis to prevent thrombotic events while increasing bleeding risk. In patients with AF and CCS, antithrombotic drugs can be either antiplatelet drugs or oral anticoagulation (OAC). Aspirin and $\mathrm{P} 2 \mathrm{Y}_{12}$ lead to an inhibition of glycoprotein Ilb/Illa, a fibrinogen receptor that aids platelet activation. Aspirin blocks the formation of thromboxane $A_{2}\left(T_{x} A_{2}\right)$ limiting platelet aggregation and also reduces gastric mucus secretion. OAC either inhibits factor $\mathrm{Xa}$ (FXa) or thrombin to reduce clotting formation. Both medications reduce thrombotic events such as ischaemic stroke (mainly $\mathrm{OAC}$ ) and coronary ischaemic events (antiplatelets) but increase bleeding risk, that is, gastric bleeding. Potential protection may arise from proton pump inhibitors (PPIs) and histamine H2 receptor ( $\mathrm{H} 2$ blockers) may provide protection by reducing stomach acid production. Adapted from Collet et al. ${ }^{2} \mathrm{AF}$, atrial fibrillation; CCS, chronic coronary syndrome.

\section{CONCLUSION}

In conclusion, the authors shed some new light on the dual antithrombotic therapy of patients with AF and concomitant CCS. While not recommended without acute coronary events and certainly related to an increased risk of bleeding, it represents the clinical reality in many cases. Whereas the current study suggests that aspirin or a P2Y 12 inhibitor may be equivalent, not much is known on a potential net clinical benefit for the prevention of thrombotic events and which patients may benefit most. Randomised trials on the type of antithrombotic agent and optimal antiplatelet drug, their dosing and duration of therapy are lacking. Utilisation of PPI therapy in patients receiving antithrombotic therapy may be another target for optimisation of clinical management, especially since it further reduces bleeding events. Therapy with PPI is safe, and the benefits outweigh the risk in patients where therapy is indicated. ${ }^{8}$
The personalised treatment of patients with concomitant AF and CCS remains complex and more evidence is required to make guideline recommendations.

Twitter Shinwan Kany @kany_md

Contributors SK wrote the initial draft of the manuscript. SK and RS worked on the figure and the final manuscript.

Funding The authors have not declared a specific grant for this research from any funding agency in the public, commercial or not-for-profit sectors.

Competing interests None declared.

Patient and public involvement Patients and/or the public were not involved in the design, or conduct, or reporting, or dissemination plans of this research.

Patient consent for publication Not required.

Provenance and peer review Commissioned; internally peer reviewed.

\section{(2) \\ OPEN ACCESS}

Open access This is an open access article distributed in accordance with the Creative Commons Attribution
Non Commercial (CC BY-NC 4.0) license, which permits others to distribute, remix, adapt, build upon this work non-commercially, and license their derivative works on different terms, provided the original work is properly cited, appropriate credit is given, any changes made indicated, and the use is non-commercial. See: http:// creativecommons.org/licenses/by-nc/4.0/.

(c) Author(s) (or their employer(s)) 2021. Re-use permitted under CC BY-NC. No commercial re-use. See rights and permissions. Published by BMJ.

\section{A) Check for updates}

To cite Kany S, Schnabel R. Heart 2021:107:1690-1691.

Published Online First 12 August 2021

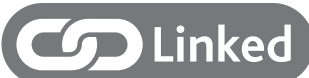

- http://dx.doi.org/10.1136/heartjnl-2021-319321

Heart 2021:107:1690-1691.

doi:10.1136/heartjnl-2021-319830

\section{ORCID iDs}

Shinwan Kany http://orcid.org/0000-0001-8113-733X Renate Schnabel http://orcid.org/0000-0001-71709509

\section{REFERENCES}

1 Magnussen C, Niiranen TJ, Ojeda FM, et al. Sex differences and similarities in atrial fibrillation epidemiology, risk factors, and mortality in community cohorts: results from the BiomarCaRE Consortium (biomarker for cardiovascular risk assessment in Europe). Circulation 2017:136:1588-97.

2 Collet J-P, Thiele H, Barbato E, et al. 2020 ESC guidelines for the management of acute coronary syndromes in patients presenting without persistent ST-segment elevation. Eur Heart J 2021:42:1289-367.

3 Gibson CM. Going polymer free and dual antiplatelet free earlier. J Am Coll Cardiol 2017;69:172-5.

4 Fukaya H, Ako J, Yasuda S. Aspirin versus P2Y inhibitors with anticoagulation therapy for atrial fibrillation. Heart 2021;107:1731-8.

5 Yasuda S, Kaikita K, Akao M, et al. Antithrombotic therapy for atrial fibrillation with stable coronary disease. N Eng/ J Med 2019;381:1103-13.

6 Steinberg BA, Kim S, Piccini JP, et al. Use and associated risks of concomitant aspirin therapy with oral anticoagulation in patients with atrial fibrillation. Circulation 2013:128:721-8.

7 Koo B-K, Kang J, Park KW, et al. Aspirin versus clopidogrel for chronic maintenance monotherapy after percutaneous coronary intervention (HOST-EXAM): an investigator-initiated, prospective, randomised, openlabel, multicentre trial. The Lancet 2021;397:2487-96.

8 Moayyedi P, Eikelboom JW, Bosch J, et al. Safety of proton pump inhibitors based on a large, Multi-Year, randomized trial of patients receiving rivaroxaban or aspirin. Gastroenterology 2019:157:682-91.

9 Bhatt DL, Cryer BL, Contant CF, et al. Clopidogrel with or without omeprazole in coronary artery disease. New England Journal of Medicine 2010;363:1909-17. 